ReVISTA GRIFOS 113

\title{
ENVELHECIMENTO DO CAMPO E O MOVIMENTO DE MULHERES CAMPONESAS: DESAFIOS E PERSPECTIVAS \\ Elisiane de Fátima Jahn*
}

\begin{abstract}
Resumo
Pessoas idosas sempre existiram na história da humanidade, apesar de representarem um fato isolado, devido à presença - em números relativamente baixos - de velhos/as na sociedade. Esse fato, que atualmente é corriqueiro, devido ao processo de envelhecimento populacional, nos últimos períodos tem sido discutido amplamente por diversos setores da sociedade. Segundo Netto (2002), o século XX foi, principalmente, um século de crescimento populacional; já o XXI será um século de envelhecimento populacional. $\mathrm{O}$ autor afirma que as taxas de crescimento da população brasileira, entre as décadas de 1950 e 1970, giravam em torno de 3\% ao ano. A partir daí, houve um processo de declínio, com redução acentuada dos níveis de fecundidade. Dessa forma, a alta fecundidade do passado, aliada à redução da mortalidade em todas as idades, resultará em um crescimento elevado da população idosa nos próximos 30 anos, constituindo o que está sendo chamado de "onda idosa". Esse fenômeno também se evidencia no campo ou na roça, principalmente devido à migração dos jovens para as grandes cidades. Essa nova conjuntura da população camponesa, aos poucos, vai se tornando um desafio no que diz respeito à concretude da reprodução da vida, da produção de alimentos e da organização popular. Ao mesmo tempo, também pode ser inspirador de novas perspectivas, visto que, segundo as pesquisas, geralmente os/as idosos/as possuem um grau de satisfação maior quando seus vínculos sociais são mais amplos do que as relações familiares. Dessa forma, este artigo procura dialogar sobre estes três temas, que se entrelaçam no cotidiano camponês: o envelhecimento, o campesinato e o Movimento de Mulheres Camponesas (MMC), em um exercício teórico, amoroso e militante.
\end{abstract}

Palavras-chave: Envelhecimento. Migração de jovens. Movimento de Mulheres Camponesas (MMC).

* Mestre em Educação pela Universidade Federal do Rio Grande do Sul (UFRGS), educadora popular e militante do MMC.Email: j.elismmc@gmail.com 


\section{Introdução}

Este artigo procura dialogar sobre três temas que se entrelaçam no cotidiano camponês: o envelhecimento, o campesinato e o Movimento de Mulheres Camponesas (MMC). Metodologicamente se caracteriza como um estudo crítico e propositivo, na medida em que associa dados, informações e percepções obtidas através da inserção militante da autora, alicerçada por um exercício crítico e fundamentado na literatura que, entretanto, não se esgota nessa relação na medida em que propõe mudanças e perspectivas para o $\mathrm{MMC}$ no que se refere à atuação do movimento em torno da problemática do envelhecimento no campo, em decorrência principalmente do fenômeno associado à migração de jovens rurais.

Pessoas idosas sempre existiram na história da humanidade, apesar de representarem um fato isolado, devido à presença - em números relativamente baixos - de velhos/as na sociedade. Esse fato, devido ao processo de envelhecimento populacional nas últimas décadas, tem sido discutido amplamente por diversos setores da sociedade. Segundo Netto (2002), o século XX foi, principalmente, um século de crescimento populacional; já o XXI será um século de envelhecimento populacional. $\mathrm{O}$ autor afirma que as taxas de crescimento da população brasileira, entre as décadas de 1950 e 1970, giravam em torno de 3\% ao ano. A partir desse período houve um processo de declínio, com redução acentuada dos níveis de fecundidade. Dessa forma, a alta fecundidade do passado, aliada à redução da mortalidade em todas as idades, resultará em um crescimento elevado da população idosa nos próximos 30 anos, constituindo o que está sendo chamado de "onda idosa".

Esse fenômeno também se evidencia no campo ou na roça, principalmente devido à migração dos jovens para as grandes cidades. Essa nova conjuntura da população camponesa, aos poucos, vai se tornando um desafio no que diz respeito à concretude da reprodução da vida, da produção de alimentos e da organização popular. Ao mesmo tempo, também pode ser inspirador de novas perspectivas, visto que, segundo pesquisas, geralmente os/as idosos/as possuem um grau de satisfação maior quando seus vínculos sociais são mais amplos do que as relações familiares, problematização esta que se constitui em um desafio para o MMC. 


\section{Impactos do envelhecimento para o indivíduo e a sociedade $^{1}$}

O fenômeno do envelhecimento populacional tem provocado impacto tanto para o indivíduo quanto para a sociedade, pois, ao viver em uma sociedade baseada na produtividade e em padrões jovens de estética e beleza, envelhecer significa reduzir a produtividade e perder uma beleza até então considerada ideal.

Uma das primeiras questões que necessitam atenção nessa discussão é que a maioria das pessoas não se prepara para envelhecer. Segundo Debert (1999), há mesmo uma negação do próprio envelhecimento, uma recusa em pensá-lo ou planejálo devido aos estereótipos de beleza e padrões socialmente estabelecidos. Uma forte razão para essa recusa é a imagem negativa e pejorativa associada ao velho/velhice, que remete a imagens de traste, problema, inutilidade, dependência, perda e impotência.

Assim, um dos impactos para o indivíduo é a perda de seus papéis sociais, aliada ao vazio experimentado por não encontrar novas funções na sociedade, em que, muitas vezes, passam de produtores a apenas consumidores. Esse fenômeno pode ser encontrado na teoria do desengajamento, que admite que, ao envelhecer, as pessoas vão sendo afastadas dos papéis que até então lhe atribuíam determinadas funções para assumirem outros papéis. No caso do campo, isso pode ser evidenciado a partir do comando da propriedade rural e do desempenho do trabalho, que aos poucos vai sendo assumido pelos/as filhos/as.

Outro elemento causador de impacto para o indivíduo idoso é a sua associação à improdutividade, por estar sendo excluído do mundo do trabalho. Esse impacto é mais observado na população urbana, uma vez que, ao se aposentarem, os indivíduos são afastados do trabalho, que é algo que os identificava por fazer parte de toda a sua vida produtiva. Logo, ao afastar-se dele, os idosos deixam de ser produtivos para serem olhados como improdutivos, como peso para a previdência e para a sociedade.

Nesse ponto,é possívelver algumas mudanças no meio urbano, visto que muitos/as idosos/as estão retornando ao trabalho formal e informal após se aposentarem. A um primeiro olhar, isso pode parecer um avanço, frente ao tratamento improdutivo dado aos/às idosos/as. No entanto, há de se perceber que, com o decorrer dos anos, o dinheiro da aposentadoria vai ficando insuficiente devido
Revista Grifos 115 $1 \mathrm{O}$ texto descrito é fruto de uma síntese realizada pela autora do artigo, baseada em estudos sobre a temática. Por esse motivo as fontes não aparecem diretamente no texto, mas apenas ao final, nas Referências Bibliográficas. 
2 A palavra é originária do grego pater, e se refere a um território governado por um patriarca, de onde deriva a palavra pátria. País, pátria, patriarcado e pagão tem a mesma raiz, assim como PAI. ao cálculo realizado pelo fator previdenciário e, para manterem as mesmas condições de antes, idosos/as retornam ao trabalho. Além disso, as empresas lucram em readmitir idosos/as, pois são isentos de pagamento de INSS, vale alimentação e vale transporte.

Para as mulheres, que vivem mais, outra consequência é a ocorrência de alta porcentagem de viuvez e, em alguns casos, de solidão. Ainda, ocorre a perda de papéis sociais e há uma carga maior de preconceitos, visto que o estereótipo feminino é mais fortemente atrelado à beleza do corpo, que ao envelhecer sai dos padrões estabelecidos e, assim, as mulheres ficam "feias", não desejadas e improdutivas (trabalho e fertilidade).

Para a sociedade brasileira, o impacto maior do aumento da população idosa será na repartição dos parcos recursos existentes, visto que haverá uma grande quantidade de aposentados/as e quase a mesma proporção de pessoas em idade produtiva. No campo da saúde, há um impacto com relação às doenças infectocontagiosas (necessitam de menor tempo de acompanhamento médico hospitalar) que cedem lugar às crônico-degenerativas (glândulas endócrinas e metabólicas, aparelho circulatório e respiratório etc., que necessitam de maior atenção e acompanhamento médico). A resposta a essa mudança, em geral, tem sido insuficiente.

Já com relação ao campo (meio rural), que está ficando velho e masculino, um dos grandes problemas é a sucessão rural, visto que os jovens (especialmente as mulheres, por estudarem mais e porque suas mães não querem que as filhas passem o mesmo trabalho que elas) cada vez mais estão migrando para as cidades, não permanecendo no campo.

\section{Movimento de Mulheres Camponesas: história de luta e resistência}

As mulheres e suas formas de resistência contra a violência e a opressão social e masculina foram invisibilizadas pela história oficial. Pouco se sabe da sua existência e os poucos registros que se têm mostram as mulheres atreladas a elementos desastrosos, pecaminosos, desprezíveis e que foram alguém porque eram esposas de alguém importante que as fez ser assim. Eram santas ou mortas, sacrificadas pela causa dos outros.

Diante dessa exclusão histórica, construída pelo patriarcado ${ }^{2}$, que tratou de invisibilizar tanto as mulheres como suas lutas, é que surgem movimentos específicos de mulheres. $\mathrm{O}$ MMC pode 
ser citado como um exemplo da necessidade de visibilização das camponesas como "gente" que, no Estado do Rio Grande do Sul, organizou-se a partir da Organização da Mulher da Roça (OMR) e do Movimento de Mulheres Trabalhadoras Rurais (MMTR).

A forma com que as mulheres reivindicaram e se organizaram datam de longo tempo e partem do questionamento da construção histórica do papel que essas têm ocupado nos espaços de poder e de decisão.

Mesmo havendo longa data de afirmação dos movimentos feministas, tanto na Europa quanto no Brasil, o fato de as mulheres se organizarem nunca foi tranquilo, inclusive no interior das organizações de esquerda que, por muito tempo, acreditaram que todos os problemas das mulheres seriam resolvidos assim que fosse realizada a transformação nas estruturas do modo de produção capitalista, ou mesmo que a organização específica das mulheres dividiria a luta da classe trabalhadora.

Não raro as feministas recebem o rótulo de que toda feminista é mal resolvida, é mal amada. Também não é raro que muitos ditos companheiros preferem se relacionar afetivamente com aquelas mulheres que, de certa forma, não representam ameaça para eles. $\mathrm{O}$ temor da palavra feminista ainda é muito forte (GEBARA, 2001, p. 15)

Isso pode ser justificado pelo fato de que a construção da opressão sobre as mulheres é histórica e intrinsecamente ligada à cultura patriarcal que ainda entende as mulheres como propriedades masculinas e menos capazes, mesmo diante das muitas mudanças no cotidiano das ações práticas, sociais e políticas que se estão vivenciando na sociedade contemporânea.

Conforme Beauvoir (1967, p. 320):

[...] marido é o senhor, a mulher sua propriedade. As mudanças sociais, a prática do birth-controß ${ }^{\beta}$ enfraqueceram bastante esses motivos. Mas a vontade de manter a mulher em estado de dependência perpetua as proibições de que a cercam ainda.

Dessa maneira, as mulheres que viviam a opressão no seu cotidiano foram, aos poucos, construindo uma leitura diferente da realidade em que estavam inseridas. Perceberam a necessidade de construir espaços de poder, com a convicção de que, para chegarem a ter poder, voz e vez não havia alternativa a não ser se organizarem. 
Para as camponesas, segundo registros históricos, esse processo de reconhecimento de seu trabalho no campo fora uma necessidade primeira, visto que, mesmo desempenhando as mesmas funções que os homens, socialmente seu trabalho era visto como uma "ajuda” e, logo, não era trabalho. Portanto, a mulher não era reconhecida como trabalhadora rural e não possuía direito e acesso a benefícios concedidos parcialmente para os homens rurais.

Segundo Paulilo (2009):

A categoria "trabalho", seja ele remunerado ou não, sempre se mostrou relevante para o pensamento feminista. Considerar trabalho as inúmeras atividades desenvolvidas pela mulher no lar e nas pequenas propriedades agrícolas foi uma forma de torna-las visíveis e mais valorizadas. [...] É ela (categoria trabalho) que está no cerne de uma das principais conquistas dos movimentos de mulheres agricultoras que, junto com outros movimentos sociais ligados ao campo, lutou para que as esposas envolvidas na produção agrícola familiar fossem consideradas "produtoras rurais" e não "do lar”. (PAULILO, 2009, p. 179).

Esse movimentar-se das camponesas na década de 1980 também é fruto de um conjunto de ações e atividades de movimentos de mulheres que vinham se organizando na Europa na década de 1970, e se reorganizando no Brasil no período de pós-ditadura militar. Segundo a pesquisa realizada pelo Comitê das Organizações Profissionais Agrícolas da CEE (COPA, 1988), na Europa, os anos 70 foram marcados por uma reação das mulheres rurais à dureza de seu trabalho agrícola, estando presente a aspiração de serem mais que "donas de casa". Segundo a mesma fonte, nos anos 80 ocorre uma mudança no sentido da valorização das mulheres como "profissionais da agricultura". Paulilo segue afirmando que essa mudança é observada no Brasil,"pois é nesses anos que surge no Sul o Movimento de Mulheres Trabalhadoras Rurais (MMTR) que, mais tarde, se expandiria para todo o país”(PAULILO, 2009, p. 181).

Dessa forma, a participação das mulheres trabalhadoras rurais - enquanto organização social - se constrói a partir da necessidade da conquista de direitos, no reconhecimento da profissão de trabalhadoras rurais e do trabalho realizado pelas mulheres, especialmente na década de 1980.

Em alguns registros, consta que, inicialmente, as mulheres da roça atuavam em movimentos, pastorais e organizações 
sociais mistas cujas demandas de mulheres, no entanto, não eram reconhecidas, valorizadas ou mesmo encaminhadas.

Por esse conjunto de elementos, vinculados à historicidade e ao momento conjuntural de abertura política no pós-ditadura militar, aliada às discussões em torno da Constituição Federal de 1988, as mulheres do campo no Estado do Rio Grande do Sul se organizam, inicialmente, na OMR (em 1983) e, posteriormente, no MMTR/ RS (em 1989), o que, a partir de 2004, compõe o MMC/RS. Assim:

A condição de vida a que estavam submetidas as mulheres camponesas: a sobrecarga de trabalho, o não reconhecimento e não valorização, a violência, exploração e a discriminação, são o núcleo de emergência da Organização das Mulheres da Roça, embrião do que viria a ser mais tarde o MMTR RS, que, por sua vez, compõe o MMC Brasil. (CONTE; DARON; MARTINS, 2009. p. 94).

E, segundo Stephen (1996):

[...] as preocupações iniciais do MMTR eram relacionadas com a saúde da mulher, licença maternidade e à implementação de benefícios previdenciários como aposentadoria e outros já assegurados às trabalhadoras urbanas, além do reconhecimento do trabalho da mulher rural e sua integração individual nos sindicatos e cooperativas... Se os primeiros objetivos eram semelhantes, as mudanças de rumo também o foram, pois "mesmo que ainda firmemente enraizado em uma análise que ressalta o lugar da classe trabalhadora... na estrutura econômica capitalista, o MMTR aos poucos tem trabalhado com mais ênfase os aspectos culturais e sociais das diferenças referentes a gênero no Brasil (STEPHEN, 1996, p. 36-7).

Segundo registros de arquivos da Secretaria Nacional do MMC, ao longo dos tempos a demanda de construção de um movimento social foi sendo transformada em necessidade concreta, representando os muitos anseios das trabalhadoras rurais que, imergidas em cantos e palavras de ordem, foram construindo um espaço próprio e autônomo que as identificava, unia e fazia resistir contra todas as formas de opressão, exploração e violência a que suas vidas estavam envolvidas, seja nos espaços privados ou domésticos, ou contra o agronegócio ${ }^{4}$, empresas transnacionais, monoculturas e a própria cultura patriarcal.

Nesse processo de lutas é que se firmou a construção do movimento autônomo de mulheres. Refletindo e cantando músicas como "pra mudar a sociedade do jeito que a gente quer, participando
4 Forma ou relação de produção agrícola, baseada na visão industrial e comercial envolvendo a cadeia produtiva de grande escala, na monocultura para exportação em grandes extensões de terra. 
5 A Via Campesina é uma articulação de Movimentos e Organizações sociais do campo. Fazem parte da Via Campesina RS o MMC, o Movimento dos Pequenos Agricultores (MPA), o Movimento dos Trabalhadores Rurais Sem Terra (MST), o Movimento dos Atingidos pelas Barragens (MAB), a Comissão Pastoral da Terra (CPT), a Pastoral da Juventude Rural (PJR) e a Federação dos Estudantes de Agronomia do Brasil. sem medo de ser mulher", "entrei na luta, da luta eu não fujo, pelos direitos da luta eu não fujo, pela igualdade, da luta eu não fujo, pra construir uma nova sociedade", participando das lutas e dos momentos de formação, as mulheres trabalhadoras alimentavamse de uma forte mística e convicção, que lhes dava forças para enfrentar a dureza da sua realidade e das lutas que vinham travando como organização. O movimento foi sendo espaço aglutinador de milhares de vozes femininas ocultadas e silenciadas por uma sociedade machista burguesa (DARON, 2003, p. 66).

Ainda segundo os mesmos registros, para se chegar à identidade de movimento social, popular, de classe, feminista e camponês houve muita reflexão forçada pela materialidade colocada, ou seja, a luta das mulheres foi caminhando para essa direção. Tal afirmação fica explícita no documento-tese de fundação do MMC Brasil (2004), no trecho descrito abaixo:

Nos anos da década de 1980 se consolidaram diferentes movimentos de mulheres nos estados, em sintonia com o surgimento de vários movimentos do campo. Nós trabalhadoras rurais construímos a nossa própria organização. Motivadas pela bandeira do Reconhecimento e Valorização das Trabalhadoras Rurais, desencadeamos lutas como: a libertação da mulher, sindicalização, documentação, direitos previdenciários (salário maternidade, aposentadoria,...), participação política entre outras. Aos poucos, os movimentos de mulheres foram se fortalecendo nos estados, avançando nas lutas específicas e gerais, na organização da base, na formação de lideranças e na compreensão do momento histórico em que vivemos. A partir desta leitura e movidas pelo sentimento de fortalecer a luta em defesa da vida, começamos a potencializar e unificar o movimento autônomo para ter expressão e caráter nacional. E esta consolidação acontece após muitos debates e discussões, com 1.500 mulheres reunidas em Brasília durante o I congresso nacional do MMC em março de 2004.

Atualmente, o MMC é um movimento social nacional e autônomo, de mulheres do campo, organizado em 23 estados do Brasil e que compõe a Via Campesina do Brasil ${ }^{5}$. Nessa organização, são as próprias mulheres que pensam e vivem o jeito de fazer movimento, desde os grupos nas comunidades até as instâncias de direção nacional.

O MMC possui uma trajetória de mais de 20 anos de organização das mulheres trabalhadoras rurais nos Estados do Rio Grande do Sul e de Santa Catarina. Articula-se a partir 
de mulheres que compartilham da forma de organização do

movimento e de grupos localizados nas comunidades rurais, que são denominados grupos de base.

As camponesas afirmam que essa trajetória do MMC vem mostrando que, juntamente com as discussões e as práticas das novas relações, há necessidade da construção de um projeto popular de agricultura camponesa, fundamentado nos princípios da agroecologia, no respeito à biodiversidade e no combate a todas as formas de violência praticadas contra as mulheres e a classe trabalhadora.

Segundo observações militantes, a ação coletiva, a incidência na sociedade, o combate a todas as formas de violência praticada contra as mulheres, a mudança na sua vida cotidiana, a construção de um projeto de agricultura camponesa - baseado em novas relações entre as pessoas e destas com a natureza - têm sido a marca principal do MMC neste último período. Suas ações têm visado à construção cotidiana de relações diferentes com as mais variadas formas de vida e de negação a tudo aquilo que oprime e violenta as mulheres e a classe trabalhadora.

De outro lado, as camponesas vêm afirmando sua importância no empoderamento das mulheres do campo, na ampliação de seus horizontes, pautadas no entendimento de que a vida vai além do espaço doméstico e da horta. Entendem que a condição de mulheres, construída histórica e socialmente, não pode ser um fator que as leve eternamente a viver sob a sombra dos homens, sejam eles pais, irmãos, maridos ou companheiros.

As mulheres camponesas obtiveram muitas conquistas nesses anos de caminhada. Um exemplo disso é o reconhecimento de sua profissão como trabalhadora rural, o acesso a direitos (como, por exemplo, aposentadoria e salário maternidade), a possibilidade de seguir com os estudos, os avanços com relação ao combate à violência doméstica e familiar e o entendimento de que sua vida pode ser melhor indo além do espaço doméstico.

De acordo com resoluções da $6^{\mathrm{a}}$ Assembleia do $\mathrm{MMC} / \mathrm{RS}$ (2005, p. 28):

Nossa história está enraizada na missão do MMC, fortalecida nos princípios, valores e mística das camponesas. Assim, refletimos a realidade vivenciada por nós, mulheres e homens, e a convicção de transformá-la, propomos o Projeto Popular de Agricultura Camponesa na ótica feminista e revolucionária, bem como um Projeto Popular de Sociedade para o Brasil. 
Para superarmos o modelo vigente precisamos nos alimentar nos avanços e conquistas que tivemos, superando os desafios e projetando novos rumos para o MMC. Reafirmamos nossas lutas centrais com seus eixos fundamentados na Mudança nas Relações Sociais de Gênero e de Classe, no Projeto Popular de Agricultura Camponesa, na Ampliação dos Direitos Sociais, no Projeto Popular para o Brasil e no Feminismo, propondo linhas de ação para alcançar as conquistas que desejamos.

No entanto, conforme se percebe na citação anterior, a cultura patriarcal e machista da atual sociedade ainda faz com que a opressão sobre as mulheres seja cada vez mais sutil. Dessa forma, as camponesas afirmam em suas falas e elaborações que ainda há necessidade de as mulheres de se organizarem, fazendo com que o Movimento vá se adequando às novas demandas, sempre acreditando que "juntas temos força para resistirmos e lutarmos pela construção de uma sociedade feminista e socialista" (CARTILHA RESOLUÇÕES 6a ASSEMBLEIA MMC/RS, p. 28).

\section{A Mulher Idosa no Campo: vivências, memórias e trajetórias}

Discutir mulher e campo, nos dias atuais, nos remete a dialogar com o tema do envelhecimento, isso porque vivemos em uma realidade em que, comparada a outras décadas, há uma pequena porcentagem de famílias residindo no meio rural que, em sua maioria, têm sido compostas por idosos/as e por homens. A articulação desse tema com as vivências, as memórias e as trajetórias se constitui a partir do reconhecimento de que as pessoas são fruto de uma história social, de acontecimentos e de determinado contexto, portanto, carregadas de experiências e memórias históricas.

O processo de envelhecimento do campo foi sendo incentivado desde o início da industrialização no Brasil, mas foi acentuado especialmente a partir da década de 1960, quando da implantação da chamada "revolução verde".

Segundo Andrades e Ganimi (2007), a chamada modernização da agricultura - fenômeno mundial da década de 1950 que demarcou o segundo período de desenvolvimento do setor agrícola - no Brasil foi implementada nas décadas de 1960 e 1970. Com o slogan de acabar com a fome no mundo, a agricultura passa a adotar sementes híbridas em sua forma 
de produzir, as quais exigiam adubação química e utilização de defensivos (venenos). Ainda, a adoção dessas práticas agrícolas veio somada a uma utilização maior de equipamentos mecânicos pesados, tais como tratores e colheitadeiras.

Esse fenômeno, que compreendeu o uso de novas tecnologias, resultando em uma expansão na produção de alimentos e no rápido aumento na utilização de fertilizantes químicos, demarcou a entrada acelerada do agronegócio exportador no campo. Por outro lado, a agricultura camponesa passou a viver um dilema, um conflito na forma de produzir, atrelado à perda da cultura camponesa de produção de alimentos e de migração de muitos jovens do campo para a cidade.

Aos agricultores/as que tinham suas sementes, produziam sem utilização de venenos e possuíam uma relação diferenciada com a terra e o meio em que viviam, foram sendo atribuídos codinomes como atrasados, "jecas", sujos, feios. Tudo que era característico e cultural do campo passa a ser considerado sinônimo de atraso.

No campo, foi oferecida a educação mínima (primeiras séries do ensino fundamental), à qual as mulheres tiveram pouco acesso. Aos jovens, coube a dificuldade para estudar e as poucas possibilidades de lazer. Houve um incentivo cultural para a vida na cidade, supostamente mais feliz, com maior diversão e possibilidades de ter renda fixa, com acesso facilitado ao estudo e ao consumo.

As décadas de 1960 e 1970 demarcam um período no desenvolvimento da agricultura camponesa de mudanças e transformações, fazendo com que, aos poucos, os/as camponeses/ as fossem deixando o meio rural e suas formas características de produzir.

Enquanto concepção, o campesinato - que será discutido neste texto com seus fundamentos teóricos - diferem-se da concepção de agricultura familiar. Dentre as principais diferenças entre a agricultura familiar e o campesinato, segundo Carvalho (2005), destacam-se:

a) a agricultura familiar é um conceito genérico, que incorpora uma diversidade de situações específicas e particulares;

b) ao campesinato corresponde uma destas formas particulares da agricultura familiar, que se constitui enquanto um modo específico de produzir e de viver em sociedade;

c) a agricultura familiar que se reproduz nas sociedades modernas 
deve adaptar-se a um contexto socioeconômico próprio destas sociedades, que a obriga a realizar modificações importantes em sua forma de produzir e em sua vida social tradicionais;

d) estas transformações do chamado agricultor familiar moderno, no entanto, não produzem uma ruptura total e definitiva com as formas “anteriores", gestando, antes, um agricultor portador de uma tradição camponesa, que lhe permite, precisamente, adaptarse às novas exigências da sociedade;

e) o campesinato brasileiro tem características particulares - em relação ao conceito clássico de camponês - que são o resultado do enfrentamento de situações próprias da história social do país e que servem hoje de fundamento a este "patrimônio sociocultural" com que deve adaptar-se às exigências e condicionamentos da sociedade brasileira moderna. (CARVALHO, 2005, p. 26)

Para Conte, Martins e Daron (2009, p. 122), na essência o conceito de "camponês" compreende um modo de vida baseado na propriedade/posse da terra e dos recursos naturais que ela suporta, assim como a incorporação da força de trabalho do núcleo familiar, composto pelos trabalhadores diretos do processo de trabalho da unidade de produção, em que a estrutura, ao contrário daquela da empresa capitalista, não tem como fim o lucro, mas a reprodução.

Seu sistema de produção é baseado na "policultura-pecuária" (CARVALHO, 2005, p. 29), que articula atividades agrícolas de produção com a criação de animais de pequeno porte e escala, e o campesinato possui uma relação diferenciada com o ambiente em que atua, porque traz em si a perspectiva de projeto de futuro e de gerações.

Notadamente, a agricultura camponesa tradicional é

[...] profundamente inserida em um território, lugar de vida e de trabalho, onde o camponês convive com outras categorias sociais e onde se desenvolve uma forma de sociabilidade específica, que ultrapassa os laços familiares e de parentesco. (CARVALHO, 2005, p. 30).

Por esses motivos, o campesinato não pode ser apenas descrito ou identificado como agricultura de subsistência, porque dela emergem muitos outros elementos que ultrapassam os limites da produção e de reprodução social da vida; por isso, pode ser considerada como uma categoria analítica e histórica, que possui características e estratégias distintas em seu modo de produzir, pensar e reproduzir-se socialmente.

REVISTA GRIFOS - N. 34/34 - 2013 
De acordo com Fernandes, Medeiros e Paulilo (2009),

Se a relação com o mercado é característica distintiva desses produtores, as condições dessa produção guardam especificidades que se fundamentam na alocação ou no recrutamento de mão-de-obra familiar. [...] Por esses termos, a forma de alocação dos trabalhadores também incorpora referências de gestão produtiva, segundo valores sociais reconhecidos como orientadores das alternativas de reprodução familiar, condição da qual decorrem modos de gerir a herança, a sucessão, a socialização dos filhos, a construção de diferenciados projetos de inserção das gerações. (FERNANDES; MEDEIROS; PAULILO, 2009, p. 10).

Os mesmos autores afirmam ainda que o campesinato também possui elementos políticos que se associam na compreensão, que ora são positivos, ora negativos, pelo reconhecimento social a ele atribuído.

Os camponeses instauraram, na formação social brasileira, em situações diversas e singulares e mediante resistências de intensidades variadas, uma forma de acesso livre e autônomo aos recursos da terra, da floresta e das águas, cuja legitimidade é por eles reafirmada no tempo. Eles investiram na legitimidade desses mecanismos de acesso e apropriação, pela demonstração do valor de modos de vida decorrentes da forma de existência em vida familiar, vicinal e comunitária. A produção estrito senso se encontra, assim, articulada aos valores da sociabilidade e da reprodução da família, do parentesco, da vizinhança e da construção política de um "nós" que se contrapõe ou se reafirma por projetos comuns de existência e coexistência sociais. (FERNANDES; MEDEIROS; PAULILO, 2009, p. 13).

Outro elemento importante é que a forma camponesa de reprodução dos costumes, formas e jeitos de viver foi sendo transmitida entre as gerações como um legado. Assim,

$\mathrm{Na}$ construção da formação social brasileira, o modo de existir reconhecido pela forma camponesa [...] é um ideia - valor, orientadora de condutas e de modos de agregação familiar ou grupal. $\mathrm{Na}$ qualidade de valor, é um legado transmitido entre gerações, reatualizado e contextualizado a cada nova geração que investe nessa adesão política (FERNANDES; MEDEIROS; PAULILO, 2009, p. 14).

Dessa forma, a agricultura camponesa, permeada por história, resistência e cultura, também é geracional e suas lutas são sinais de resistência contra a desterritorialização e o abandono do campo. 
Nota-se que as mulheres camponesas são aquelas pessoas que atuam ligadas ao campo e à terra, na pequena propriedade, na produção de alimentos diversificados e criação de pequenos animais e no trabalho com a família. Atuam baseadas em formas diferentes de viver e se relacionar com a terra, a vida e a natureza, em uma perspectiva de deixar para as futuras gerações um ambiente saudável e diversificado para se viver.

Dentre muitos fatores, atualmente o campo vem vivenciando um gradativo êxodo rural, especialmente dos jovens, ocasionado pelo sistema agrícola e econômico, pela falta de escolas e escasso acesso a lazer e renda, o que vem acarretando um envelhecimento da população rural camponesa. Cabe dizer que o envelhecimento populacional é um fenômeno de abrangência mundial, traduzido pela diminuição progressiva das taxas de fecundidade e mortalidade e pelo aumento da expectativa de vida. Dos idosos que vivem em áreas rurais, somam-se $60 \%$ em todo o mundo.

Dados do Instituto Brasileiro de Geografia e Estatística (IBGE, 2008) vêm mostrando que $10,5 \%$ da população brasileira (20 milhões de idosos) e 13,7\% da população do Rio Grande do Sul encontram-se na faixa etária acima dos 60 anos; destes, 16,5 milhões viviam na área urbana e 3,4 milhões na área rural.

Outros dados, sistematizados pelo Instituto de Pesquisa Econômica Aplicada (IPEA, 2002), apontam que, no continente americano, vivem $12 \%$ da população mundial, da qual $28 \%$ possui mais de 60 anos. Na América Latina, em 20 anos (1980 a 2000) houve um acréscimo de $120 \%$ da população como um todo e de $236 \%$ da população idosa. Ainda, de 1990 a 2025, a população idosa mundial crescerá $2,4 \%$ ao ano, contra $1,3 \%$ de crescimento anual terrestre. Do total da população idosa brasileira, $76,7 \%$ vivem nos centros urbanos. Nos últimos anos, houve um decréscimo de $36 \%$ da população jovem e um acréscimo de $140 \%$ da população idosa no Brasil.

Estimativas apontam que, no ano de 2000, havia um/a idoso/a para cada 3,6 crianças. Em 2020, esses números passam para um/a idoso/a para cada 1,57 crianças e, em 2050, caem para um/a idoso/a para cada 0,72 crianças. Dessa forma, é possível perceber que o Brasil, assim como a maioria dos países do mundo, será um país de velhos/as.

Outro dado que nos chama a atenção é que, segundo o IBGE (2010), dos aproximados 20 milhões de idosos, 55,7\% eram do sexo feminino. E, quanto mais velho for o contingente 
estudado, maior é a proporção de mulheres, isso porque em média as mulheres vivem cinco anos mais do que os homens.

Ainda sobre a distinção entre sexos, pesquisa realizada pelo IBGE (2010) mostra que o número de mulheres idosas é maior do que o de homens nas áreas urbanas. $\mathrm{Na}$ região Sul do Brasil, a diferença entre os sexos é de 67 homens para cada 100 mulheres. No entanto, a pesquisa mostra que nas áreas rurais existem mais homens idosos do que mulheres, sendo um número de 107 homens para cada 100 mulheres.

Segundo a mesma pesquisa, essa diferença resulta da migração rural/urbana, uma vez que as idosas dirigem-se com maior frequência às cidades para residir com filhos/as, netos/as ou parentes e, também, pelo fato de os homens terem maior presença em atividades tipicamente rurais (IBGE, 2010).

Com relação ao conceito de idoso/a, a legislação brasileira considera idosas as pessoas com 60 anos ou mais (Estatuto do Idoso e Política Nacional do Idoso). No entanto, cada pessoa vive sua velhice desde onde está pisando. Sendo assim, a velhice não pode ser definida apenas de maneira cronológica, mas também pelas condições físicas, mentais, sociais e individuais. Segundo Bosi (1994), a velhice, além de ser um destino, visto que todos nós envelhecemos um pouco a cada dia, também pode ser considerada como uma categoria social, uma vez que cada sociedade vive e trata de uma forma diferenciada o envelhecimento das pessoas.

Dessa forma, pode-se afirmar que o processo de envelhecimento é um conjunto de elementos que envolvem todos os âmbitos da vida, nas esferas biológica, psicológica, social, cultural e espiritual.

Nessas diferentes esferas, segundo Doll (2012),

$\mathrm{Na}$ parte biológica, existe um processo de envelhecimento celular que leva a uma série de modificações físicas [...]. O envelhecimento psicológico se refere principalmente às capacidades cognitivas como memória, inteligência e formas de resolução de problemas [...]. As imagens da velhice nos remetem aos aspectos sociológicos do envelhecimento (DOLL, 2012, p. 403).

Portanto, há existência de muitas velhices na sociedade atual. A velhice no campo é diferente da velhice da cidade e, em cada um desses meios, a velhice se difere conforme os lugares, os aspectos sociais e econômicos ou mesmo a posição que se ocupa. 
6 A síntese descrita neste item é fruto de estudo e discussão no I Encontro Nacional do Movimento de Mulheres Camponesas, realizado de 18 a 21 de fevereiro de 2013, em Brasília, onde em uma plenária, foi conduzido pela autora do artigo um debate sobre Envelhecimento do Campo e Juventude. Para a discussão do tema juventude, a plenária contou com a participação da doutoranda Catiane Cinelli.
Para as mulheres, a vivência desse processo possui diferenças com relação ao homem, em razão das construções e atribuições socialmente construídas para ambos.

Nesse mesmo processo em que, aos poucos, vão-se desagregando velhos/as, as memórias e as vivências fazem com que a resistência seja permanente. Memórias particulares da vida das pessoas, demarcadas por acontecimentos de um passado recente, articuladas com leituras realizadas do mundo e suas significações, frutos das relações e do trabalho até então estabelecidos e construídos, são elementos fundamentais quando se pretende compreender as pessoas e o mundo social pelo qual elas fazem parte e se referem.

De acordo com observações realizadas através da inserção militante e de pesquisa nessa temática, a memória histórica e social - pelas mulheres camponesas - é explicitada na mística expressa pela concretude do seu trabalho com as sementes crioulas, o uso e a manipulação de plantas medicinais, a reprodução dos conhecimentos para as gerações mais novas, o uso da enxada e do chapéu de palha, a resistência ao agronegócio e a permanência no campo, dando exemplo de coragem, força, ousadia e teimosia em reproduzir uma cultura aprendida através das gerações.

\section{Envelhecimento do campo, desafios e perspectivas para o Movimento de Mulheres Camponesas: a guisa de considerações $^{6}$}

Para o MMC, que trabalha com mulheres que vivem no campo e que, cada vez mais, estão envelhecendo e migrando para as cidades, também podem ser apontados, previamente, alguns desafios.

Inicialmente, destaca-se que as pesquisas mostram que para os/as idosos/as o círculo de amigos/as, comparado à vivência em família, tem representado maior satisfação de vida na velhice. Dessa forma, a organização de mulheres pode ser um fator importante para essa faixa etária.

Embora as mulheres idosas do MMC continuem fazendo uma luta silenciosa (e muitas vezes não vista pelo conjunto da sociedade), de resistência ao modelo capitalista no campo, estas vêm preservando e reproduzindo saberes populares na produção de alimentos, ainda que muitas vezes lhes faltem as forças para longas marchas e mobilizações de enfrentamento. 
Dessa forma, faz-se necessária a adequação dos temas que o

Movimento pauta às necessidades e demandas desse público, para que as mobilizações e os atos de rua tenham trajetos mais curtos e incluam pautas demandadas pelas mulheres camponesas acima de 55 anos. Ainda, os materiais que o MMC produz devem ter letras grandes, desenhos e imagens, visto que - com o processo de envelhecimento - a visão periférica vai ficando desfocada e, além disso, ainda vivemos em uma realidade em que muitas camponesas não sabem ler.

Por outro lado, cada vez mais se faz necessário potencializar a entreajuda e o mutirão para o trabalho no campo, visto que, com o processo de envelhecimento, o corpo vai perdendo a força e a elasticidade, logo, o trabalho individual no campo vai se tornando mais difícil. Assim, são resgatados sentimentos de solidariedade, devido à importância - cada vez maior - das redes de relações de parentesco e vizinhança. Por outro lado, estudos apontam para uma grande satisfação dos/as idosos/as que permanecem de alguma forma vinculados/as ao trabalho que desenvolviam anteriormente.

Em decorrência da significativa migração dos jovens para a cidade, é necessário e urgente que o MMC discuta e paute políticas públicas que visem à volta desses jovens para o campo, a partir de uma reeducação escolar que valorize o rural, a geração de trabalho e renda, bem como alternativas de lazer. Além disso, é de fundamental importância que o MMC, juntamente com a Via Campesina, continue pautando e lutando por um projeto de agricultura camponesa que garanta mais dignidade para as pessoas do campo, com políticas públicas em âmbito micro e macroeconômico.

Por último, devido às práticas e elaborações do MMC evidenciarem a importância do resgate das práticas culturais, do trabalho com as plantas medicinais e das sementes crioulas, torna-se fundamental o trabalho intergeracional, visto que as camponesas idosas têm essas práticas muito evidentes em seu cotidiano, ao contrário das camponesas jovens.

Ao finalizar esse exercício, reafirma-se, a partir do próprio acúmulo militante, que novas relações com o trabalho, a terra e a vida, e entre as gerações só podem ser possíveis, segundo o MMC, com a transformação das relações sociais e a construção de um Projeto de Agricultura Camponesa. As práticas desenvolvidas por esse Movimento têm mostrado sua capacidade de síntese e leitura 
da realidade, investindo no trabalho diferenciado com as jovens camponesas, especialmente no estado de Santa Catarina, sem perder a experiência das idosas, em uma relação de construção cotidiana, geral e maior que pode servir de exemplo para outras organizações sociais e mesmo para o conjunto do MMC do Brasil.

\section{Referências}

ANDRADES, Thiago Oliveira de; GANIMI, Rosângela Nasser. Revolução verde e a apropriação capitalista, CE S Re v i s t a, Juiz de Fora, v. 21, p. 43-56, 2007.

BOSI, Ecléa. Memória e Sociedade. 16a ed. São Paulo: Companhia das Letras, 1994.

CAMARANO, Ana Amélia; KANSO, Solange. Envelhecimento da População Brasileira - Uma Contribuição Demográfica. Texto para discussão no 858. Rio de Janeiro,jan. 2002. Disponível em: <http://www. ipea.gov.br/pub/td/td_2002/td_0858.pdf> Acesso em: 20 jan. 2013

COMITÊ DAS ORGANIZAÇÕES PROFISSIONAIS AGRÍCOLAS DA CEE. As mulheres na agricultura. Bruxelas, 1988. (Mimeogr.)

DEBERT, Guita Grin. A Reinvenção da Velhice: Socialização e Processos de Reprivatização do Envelhecimento. São Paulo: Editora da Universidade de São Paulo: Fapesp, 1999.

DOLL, Johannes. Idosos do campo. In: CALDART, Roseli Salete; PEREIRA, Isabel Brasil; ALENTEJANO, Paulo; FRIGOTTO, Gaudêncio (orgs). Dicionário da educação do campo. São Paulo: Expressão Popular, 2012.

DOLL, Johannes; GOMES, Ângela; HOLLERWEGER, Leonéia; PECOITS, Rodrigo Monteiro; ALMEIDA, Sionara Tamanini de. Atividade, Desenganjamento, Modernização: teorias sociológicas clássicas sobre o envelhecimento. Estudos Interdisciplinares sobre o Envelhecimento, Porto Alegre, v. 12, p. 7- 33, 2007.

FERNANDES, Bernardo Mançano; MEDEIROS,Leonilde Servolo de; PAULILO, Maria Ignez (orgs.). Lutas camponesas Contemporâneas: Condições, dilemas e conquistas. Volume II. A diversidade das formas das lutas no campo. São Paulo: Editora UNESP; Brasilia, DF: Núcleo de Estudos Agrários e Desenvolvimento Rural, 2009.

GEBARA, Ivone. Cultura e relações de gênero. São Paulo: Centro de Educação Popular do Instituto Sedes Sapientiae (CEPIS). Outubro de 2011. 
IBGE. Instituto Brasileiro de Geografia e Estatística. Censo 2010. Disponível em: <http://censo2010.ibge.gov.br >. Acesso em: 26 jan. 2013

IBGE. Instituto Brasileiro de Geografia e Estatística. Censo 2008. Disponível em: <www.ibge.gov.br >. Acesso em: 26 jan. 2013.

MATOS, Vanessa Cristina Santos. Contradições, limites e avanços: uma história do movimento feminista marxista. RBSE, Revista Brasileira de Sociologia da Emoção, v. 8, n. 22, p. 134 -156, abr. 2009.

MIES, Maria; SHIVA, Vandana. Ecofeminismo. Lisboa: Instituto Piaget, 1993.

MMC/RS. Cartilha Resoluções da 6a Assembleia Estadual, outubro de 2005. (Documento impresso).

MMTR/RS. Síntese da trajetória. Porto Alegre: Porto \& Vírgula, n. 46, p. 19-23, 2002.

MOTTA, Alda Brito da. Velhice ou terceira idade? 4a ed. Rio de Janeiro: Fundação Getúlio Vargas Editora, 2006.

NETTO,Matheus Papaléu. Gerontologia, a velhice e o envelhecimento em visão globalizada. São Paulo: Atheneu, 2002.

PALUDO, Conceição (Org.). Mulheres Resistência e Luta em Defesa da Vida. São Leopoldo: CEBI, 2009.

PALUDO, Conceição; DARON, Vanderléia L. P. Gênero, Classe e Projeto PopularCompreender mais para lutar melhor. Caderno de formação n. 1, MMTR RS. Gráfica Battistel, Passo Fundo, nov. 2001.

PINTO, C. R. Movimentos Sociais: espaços privilegiados da mulher enquanto sujeito político. In: COSTA, A. O.; BRUSCHINI, C. (Orgs). Uma questão de gênero. Rio de Janeiro/São Paulo: Rosa dos Ventos/ Fundação Carlos Chagas, 1992.

STEPHEN, L. Relações de gênero: um estudo comparativo sobre organizações de mulheres rurais no México e no Brasil. In: NAVARRO, Z. (Org.). Política, protesto e cidadania no campo. Porto Alegre: Editora Universidade/UFRJ, 1996. 


\title{
THE COUNTRYSIDE AGEING AND THE PEASANT WOMEN'S MOVEMENT: CHALLENGES AND PERSPECTIVES
}

\begin{abstract}
Elderly people have always been in the history of humanity, even representing an isolated fact due to its relatively low number of older persons in the society. This fact, which is considered trivial due to the population ageing process, in the last decades has been largely debated in many sectors of the society. According to Netto (2002), the 20th century was considered a century of population growth, therefore, the 21 st century will be the population ageing century. The author infers that the rates of Brazilian population growth between the decades of 1950 and 1970 were about 3\% a year. Since then, it has happened a decline process with significant reduction on the fecundity levels. This way, the high fecundity of the past allied with the mortality reduction in every age, will result in an increase of older population in the next 30 years, constituting what is being called "age wave". This phenomena is also evident in the countryside, mainly because of the migration of the young people to the big cities. This new configuration of the countryside population is slowly becoming a challenge to life reproduction, food production and popular organization. At the same time, as pointed out by some studies, it also serves as inspiration of new perspectives, because the elderly people usually have a greater level of satisfaction when they have wide social relationships than just family relationships. Therefore, this paper proposes a dialogue among three issues interlaced in the countryside daily life: ageing, countryside life, Peasant Women's Movement (MMC), through a theoretical, lovely and militant practice.
\end{abstract}

Keywords: Ageing. Migration of the young. Peasant Women's Movement (MMC).

REVISTA GRIFOS - N. 34/34 - 2013 